\title{
INTERPRETATION OF COMMERCIAL CONTRACTS IN EUROPEAN PRIVATE LAW
}

\author{
Edited by \\ C.J.W. BAAIJ \\ Laura MACGREgOR \\ David CABRELLI
}

- intersentia

Cambridge - Antwerp - Chicago 


\title{
DESIGNING A METHOD FOR COMPARING INTERPRETATION METHODS
}

\author{
C.J.W. BAAIJ
}

\section{THE CHOICE OF COMPARATIVE METHODOLOGY}

\subsection{THE FACTUAL APPROACH OF THE COMMON CORE PROJECT}

As with any study in the Common Core Project, the methodology designed by the editors of this volume rests on the fundamentals of the general approach developed by Mauro Bussani and Ugo Mattei. The Common Core Project employs a factual approach to comparative law in two related respects. ${ }^{1}$

First, in a Common Core comparison, both the 'comparanda' ${ }^{2}$ and the tertium comparationis are of a factual nature. Rather than contrasting the legal rules applicable to a common legal concept, the Common Core comparatist seeks to measure how courts in different legal systems would solve a common factual problem of societal life. ${ }^{3}$ This strategy takes inspiration from the method that Rudolf Schlesinger developed in the 1960 s. ${ }^{4}$ By this method, a comparatist develops a questionnaire that asks legal scholars from different jurisdictions to explain how a set of hypothetical problems would likely be resolved in their respective legal systems. Because a Common Core comparatist, therefore,

$1 \quad$ M. Bussani and U. Mattei, 'The Common Core Approach to European Private Law' (1997) 12 Columbia Journal of European Law 344, 346.

2 Örücü uses the term 'comparanda' to refer to the objects of comparison: A.E. Örücü, 'Methodology of Comparative Law' in J.M. Smits (ed.), Elgar Encyclopedia of Comparative Law (2nd edn, Cheltenham: Edward Elgar) 560.

3 K. Zweigert and H. Kötz, An Introduction to Comparative Law, trans. T. Weir (3rd edn. Oxford: Oxford University Press, 1998) 32, 34.

4 M. Bussani and U. Mattei, 'The Common Core Approach to European Private Law' (1997) 12 Columbia Journal of European Law 344, 343-344. See R.B. Schlesinger (ed.), Formation of Contracts: A Study of the Common Core of Legal Systems (Dobbs Ferry, New York: Oceana, 1968). 
compares not the rules of law, but the application of them, the objects of comparisons are not conceptual content but predictions of factual events. ${ }^{5}$

Second, the data on which the Common Core comparatist relies is factual in nature. Rather than looking to the content of legal rules and concepts to predict how a court would resolve a given problem, the comparatist studies both legal and non-legal predictors. Put differently, it concentrates on how a court, in fact, would apply the law. Here, the Common Core Project builds on Rodolfo Sacco's

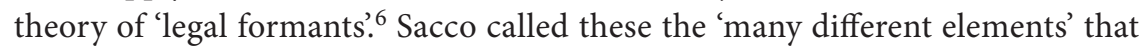
the 'living law' contains, ranging from statutory rules to scholarly commentary, to other elements that might influence a judge's thinking not contained in the ratio decidendi of the court's opinion. ${ }^{7}$ Here, therefore, formal legal rules may provide the comparatist with an answer to its question, but not because the law itself is encapsulated in the logical structure of its semantic content. Rather, as judges tend to be susceptible to arguments deduced from formal legal sources, a legal rule is simply a significant indicator of a judge's decision in a given case. ${ }^{8}$ The rules derived from legal sources are only 'legal formants' among other equally formative circumstances possibly affecting the ways courts apply the law. ${ }^{9}$ Non-legal formants may include 'policy considerations, economic and/or social facts, social context and values.' ${ }^{10}$

\subsection{ADAPTING THE GENERAL METHODS TO THE INTERPRETATION OF CONTRACTS}

The general methodological approach of the Common Core Project required further fine-tuning to adapt it specifically to a comparative study on the

5 M. Bussani and U. Mattei, 'The Common Core Approach to European Private Law' (1997) 12 Columbia Journal of European Law 344, 344, suggesting Common Core comparatists must predict what courts will do in a particular case by writing, 'we must not only know how courts have acted but we must also consider the influences to which the judges may be subject.'

6 M. Bussani and U. Mattei, 'The Common Core Approach to European Private Law' (1997) 12 Columbia Journal of European Law 344, 343-6).

7 See R. Sacco, 'Legal Formants: A Dynamic Approach to Comparative Law (Installment I of II)' (1991) 39(1) The American Journal of Comparative Law 1, 22. These formants must necessarily point harmoniously in the direction of a single outcome to legal questions, see R. Sacco, 'Legal Formants: A Dynamic Approach to Comparative Law (Installment II of II)' (1991) 39(2) The American Journal of Comparative Law 343, 343. Like Bussani and Mattei, Sacco, too, took Schlesinger's philosophy as guidance, see R. Sacco, ibid., 'Installment I of II', 27.

8 The value of formal rules of law in predicting what 'officials are going to ... do about disputes' is recognised by American Legal Realists like Karl Llewellyn (K.N. Llewellyn, The Bramble Bush: The Classic Lectures on the Law and Law School (Oxford: Oxford University Press, 1960) 6-7).

9 M. Bussani and U. Mattei, 'The Common Core Approach to European Private Law' (1997) 12 Columbia Journal of European Law 344, 352. Ibid., 355. 
interpretation of contract. First, the purpose of the study is not to ask scholars to compare the meanings courts will attribute to the language of a contract. To put it differently, the wording of the contract in question is not the tertium comparationis. After all, the comparative study involves the adoption of a single language, i.e. English. The hypothetical contractual language in the questionnaire's cases is, therefore, also drafted in English. We do not wish to compare the meaning that, for example, Croatian, Dutch, English and Spanish courts would ascribe to a contract drafted in English. It would disrupt the comparability of the results because the English, Scottish, and South African reporters will be reporting on the interpretation of contracts drafted in the language of their legal system, while all non-English-speaking reporters would describe how courts would interpret a foreign-language contract. Instead, we wish to compare how courts interpret contracts generally. Therefore, the editors of this study chose to examine how courts ascertain the meaning of contractual language. That is to say, it compares the judicial methods of interpretation. In this respect, this study's methodology follows the general Common Core approach, as it concentrates on the ways in which courts solve practical problems.

Second, a choice needed to be made regarding the features or aspects of the interpretative exercise this study would compare. We decided to focus on 'interpretation factors', that is to say, the factors a court may find relevant in deciding how to interpret a contract. These factors include the contractual language itself as well as circumstantial data, such as written or oral statements of the parties or their conduct before, during or after the closing of the agreement. Other factors may be the agreement's preamble, and practices or conventions in the particular business or industry in which the parties are operating.

Third, given the role of legal formants in the Common Core approach, reporters were asked to report on a host of legal formants affecting a court's choice of interpretation methods. These may include formal rules in a jurisdiction's civil code, solely case law, or a combination thereof. These may be rules of private law or rather rules of evidence or other procedural rules, or 'unwritten law' or legal principles.

However, in this respect, the rules of the law are not the sole source of the reporter's answer. The law is merely one of multiple possible formants. The reporter should likewise indicate whether the reason for her or his answer lies outside positive law altogether, namely in legal doctrine or scholarly writings, maxims or canons of interpretation, or any other relevant legal or extra-legal formants. We specifically wished to know whether there exists a doctrinal order or hierarchy of interpretation factors the court would adhere to, whether the interpretive question is a question of law or rather of fact, and whether a court seeks to find the common intent of the parties, the linguistic meaning of the contract at hand, or the most 'reasonable' construction of the agreement. The current comparative method invited reporters to report on all these idiosyncrasies. 


\subsection{BALANCING SAMENESS AND DIFFERENCE}

Comparative legal research intrinsically entails a fundamental dilemma. The comparatist requires a critical degree of 'sameness' to render the comparative data comparable. A reliable output of any comparative analysis relies on the comparability of the comparanda, the data under comparison. ${ }^{11}$ At the same time, the comparatist will want to avoid overlooking meaningful differences, especially those easily concealed behind superficial similarities. The challenge of securing a minimum degree of sameness while maximising the capacity of registering difference multiplies when a dozen different teams of legal scholars from different legal cultures speaking different languages provide the raw data.

First, to increase the comparability of the data on the various national legal systems, it was deemed crucial that all participants followed a single set of instructions meticulously. These instructions are included as Appendix I. The national reporters were asked to avoid answering the questionnaire by predicting what a court in their respective jurisdictions would derive from the parties' statements, conduct or other interpretation factors. As explained above, that would amount to attributing meaning to the contract rather than ascertaining how a court would attribute that meaning. Therefore, the cases and questions in the questionnaire presumed certain semantic 'facts' that all national reporters had to accept. A question might, for example, invite the reporter to assume that a text is ambiguous or whether a statement or act confirms one of the parties' readings of the contract.

Second, reporters were instructed not to add events or characters to the case, to avoid giving answers that were incomparable with those in other reports. However, if reporters felt that their answer to the question would be more precise if they contrasted it with their response if the facts were different, adding a hypothetical was considered helpful. The reporter could simply explain this by starting a sentence with, for example, 'This would have been different if ... (and so on).'

For the same reason, reporters also avoided adding information about their legal systems that were irrelevant to their response to the question at hand. Here, too, the reporter was free to include the passage in a footnote or in the opening remarks, if they found the addition nonetheless to be informative. More generally, reporters were advised to inform the reader, in a footnote, if the facts of the cases or the focus of the question did not sit comfortably with their legal system. This occurred when, for example, the assumptions underlying the case or question would appear odd in the context of their jurisdiction.

11 See for terminology, A.E. Örücü, 'Methodology of Comparative Law' in J.M. Smits (ed.), Elgar Encyclopedia of Comparative Law (2nd edn, Cheltenham: Edward Elgar) 560. 
Finally, the editors provided the reporters with an opportunity to inform the reader of the particularities of their respective legal systems without being confined by the parameters of questions and cases. To this end, reporters were asked to include opening remarks and discuss more general matters relating to contract interpretation that they believed the reader should know about their legal system in advance. Starting off with a country-specific introduction helps the reader to understand the answers to the questions better. It also compensates for the reporter's experience that the inescapable presumptions of the questionnaire are too restrictive of her or his answers. Relatedly, allowing the reporters to clarify matters that the questionnaire would otherwise prevent them from doing advances the reliability of the output of the comparative analysis. Again, one of the comparatist's most likely pitfalls is the need for comparability and comprehensibility accidentally covering up the subtler differences and peculiarities.

\section{DEVISING A METHOD OF TRANSLATION}

\subsection{COMPARATIVE LAW AND THE INEVITABILITY OF TRANSLATION}

The most elementary but generally disregarded challenge of comparative law is language. Every time a comparative legal analysis involves jurisdictions that use different general languages, law and language are inherently entwined. For the sake of accuracy and reliability, each participant in a Common Core study carries the earnest task of making every effort to choose their language with the utmost care and diligence.

The intimate connection between law and language is twofold. On the one hand, at some point in the comparative process, someone will have to translate a legal source or commentary from one language to another. This necessary act of translation does not comprise merely the rendition of foreign legal terminology. It includes grammar, syntax, terminology, phraseology, idiom, and so on. One only needs to imagine a text drafted in a language utterly unknown to the reader to appreciate the necessity and scope of legal translation involved in comparative law.

On the other hand, translating legal sources and commentary will entail some degree of comparative legal analysis to produce a translation that is sufficiently equivalent to the source text. We turn to the questions about what degree of comparative analysis it is that legal translation requires, and what counts as a 'sufficiently equivalent' translation. At this point it is sufficient to say that like any translation in any field or discipline, translating the artefacts of the law requires some comprehension and preferably significant expertise in the subject matter at hand, i.e. the foreign legal system. 
When a single bilingual comparatist carries out a comparative analysis, the translation step may go unnoticed as submerged in the comparative analysis itself. In fact, it might be difficult to distinguish the challenges of translation from challenges of comparisons. In contrast, a team of scholars may divide tasks such that some of them carry out the legal translation and the others the comparative legal analysis. In those instances, it becomes - or should become clear that legal translation and comparative legal analysis are qualitatively distinct steps, and that both are unavoidably involved in any comparative law project - at least when jurisdictions that use different general languages are involved.

The studies of the Common Core Project present the kind of group project implementing the following division of labour: the national reporters are the translators, and the editors the comparatists. The reporters report on their jurisdiction by answering the editors' questionnaire. The reporters are the experts in their respective jurisdictions. The editors are not. In contrast, the editors are comparatists. They tailor the questionnaire in a manner that will allow them to compare as meaningfully as possible the reporters' answers and draw conclusions as to the nature and degree of similarities and differences. This division of labour is crucial to maintain the reliability of the study's output.

\subsection{THE PHILOSOPHICAL UNDERPINNINGS OF THE FACTUAL APPROACH}

The division of labour between the reporter-translator and editor-comparatist calls for a careful methodology that integrates legal translation and comparative legal analysis. The philosophical underpinnings of the Common Core approach inform the development of such integrated method. Its factual approach ties the Common Core Project to certain philosophical commitments regarding the tripartite relationship between the nature of the law, the possibility of cross-cultural knowledge of the law, and the facilitative role of language in attaining such knowledge.

As to the first prong of this tripartite relationship, the Common Core comparatist makes the most intuitive yet philosophically controversial presumption: that people share a single factual reality. This supposition necessarily follows from the factual features of the method described above, namely the assumptions that a tertium comparationis is available, factual comparanda are comparable, and factual data are reliable legal formants.

The second prong of the tripartite relationship involves the presumption of a shared factual world. This is part of the Common Core Project's optimism regarding the possibility of cross-cultural legal knowledge. It shares this optimism with the functional approach to comparative law as famously developed by Konrad Zweigert and Hein Kötz in the 1980s. Zweigert and Kötz believe that 
the comparatist is capable of attaining reliable comparative legal knowledge because the law is presumptively addressing similar factual problems across societies, legal systems or legal cultures. ${ }^{12}$ While legal language and legal concepts are particular to distinct legal systems and therefore difficult or impossible to compare, they argue that analysing the law in its factual manifestation permits the comparison in 'neutral terms.' ${ }^{13}$

Third, the Common Core Project's factual approach implicitly claims that the role of language occupies key territory in facilitating comparative legal knowledge. As with all comparative analyses that involve jurisdictions using different general languages, the Common Core comparatist compares the various legal systems within a single language. To date, this language has been English. Even if a comparative study were to result in a book that uses more than one language, any individual comparative analysis itself will unavoidably be articulated in a single language that either belongs to one of the legal systems under comparison or a third language. Consequently, the Common Core Project commits to a concept of language that permits the comparatist to describe and communicate knowledge of a shared factual world across different languages. Put differently, it presumes the cross-lingual transferability of legal knowledge. It commits to the possibility that the comparatist translates information about a given legal system from one general language into another without corrupting the content of that information. Whether comparative knowledge can be transmitted from one language to another perfectly or imperfectly, the Project assumes issues of translation will not radically obstruct the possibility of comparative legal knowledge.

\subsection{REFUTING THE RELATIVIST CRITICISM}

Its philosophical underpinnings show that the Common Core Project enjoys a certain optimism as to the feasibility of translation facilitating the comparison of legal formants in distinct legal systems or cultures. This type of methodological optimism, originating from the factual understanding of law, knowledge and translation, has been the subject of harsh criticism: adherents to philosophical relativism contend that a shared factual world is lacking, and comparative legal knowledge is therefore precluded in a radical way. This criticism fails to convince, however, and refuting the inconsistency of its philosophical implications signposts the method of translation most appropriate for this book's comparative study.

\footnotetext{
12 K. Zweigert and H. Kötz, An Introduction to Comparative Law, trans. T. Weir (3rd edn. Oxford: Oxford University Press, 1998) 32, 38, 43, 45.

13 Ibid., 10-11.
} 
Legal relativism holds that distinct legal cultures, especially the common law and civil law cultures, are incommensurable because our experience with, and perception of, reality itself is conditioned and confined by the culture in which we find ourselves. ${ }^{14}$ Without a meta-cultural vantage point, and thus without a shared experience of a factual reality across legal cultures, comparative knowledge is flawed at best and fictional at worst, the critique goes. ${ }^{15}$ Any similarity between legal rules, concepts or other artefacts of legal culture, let alone a 'common core', is the product of an idealised similarity, unavoidably caused by the comparatist's inherent predispositions. ${ }^{16}$

Linguistic relativism entails, similarly, that our experience with the world in which we find ourselves originates from and is confined to the language with which we learned to experience the world to begin with. ${ }^{17}$ In this respect, language embodies a grid or framework of intelligibility, a conceptual filter through which we experience reality. ${ }^{18}$ As languages provide the categories through which the world presents itself, languages are incommensurable. ${ }^{19}$ Hence, as speakers of different languages fail to share a single factual universe, a comparatist is radically barred from communicating legal knowledge from one language into another. ${ }^{20}$ Put differently, legal translation stands in the way of a comparatist producing reliable comparative legal knowledge.

14 P. Legrand, 'The Same and the Different' in P. Legrand and R. Munday (eds.), Comparative Legal Studies: Traditions and Transitions (Cambridge: Cambridge University Press 2003) 265-268.

15 Ibid., 252-253, 281-282, 284; P. Legrand, “Il n'y a pas de hors- texte": Intimations of Jacques Derrida as Comparatist-at-Law' in P. Goodrich, F. Hoffmann, M. Rosenfeld and C. Vismann (eds.), Derrida and Legal Philosophy (London: Palgrave Macmillan, 2008) 138; P. Legrand, 'European Legal Systems Are Not Converging' (1996) 45(1) International and Comparative Law Quarterly 52, 59, 75; P. Legrand, 'Econocentrism' (2009) 59(2) University of Toronto Law Journal 215, 215.

16 P. Legrand, 'The Same and the Different' in P. Legrand and R. Munday (eds), Comparative Legal Studies: Traditions and Transitions (Cambridge: Cambridge University Press, 2003) 240, 284.

17 J.E. Joseph, 'Indeterminacy, Translation and the Law' in M. Morris (ed.), Translation and the Law (Philadelphia: Benjamins, 1995) 17

18 S. Fish, Doing What Comes Naturally: Change, Rhetoric, and the Practice of Theory in Literary and Legal Studies (Durham, NC: Duke University Press, 1989) 394-396, 563 n. 31; D. Patterson, Law and Truth (Oxford: Oxford University Press, 1996) 101; R. Phillipson, English-Only Europe? Challenging Language Policy (New York: Routledge 2003) 108.

19 For example, J. Ainsworth, 'Lost in Translation? Linguistic Diversity and the Elusive Quest for Plain Meaning in the Law' in L. Cheng, K.-K. Sin and A. Wagner (eds.), The Ashgate Handbook of Legal Translation (Farnham: Ashgate 2014) 44; J. Boyd White, 'Law as Rhetoric, Rhetoric as Law: The Arts of Cultural and Communal Life' (1985) 52 The University of Chicago Law Review 684, 690, 696; J. Boyd White, 'Thinking About Our Language' (1987) 96 The Yale Law Journal 1960, 1962.

20 J. Boyd White, 'Thinking About Our Language' (1987) 96 The Yale Law Journal 1960, 1962-1964; B. Großfeld, Core Questions of Comparative Law, trans. V. Grosswald Curran (Durham, NC: Carolina Academic Press, 2005) 46. 
Both legal and linguistic relativism, and the consequent critique of the Common Core's factual approach suffers from a fatal paradox. ${ }^{21}$ The relativists' claim that cultures or languages lack a single framework of reference from within which to experience and observe the world itself implies a single framework of reference. After all, the very idea of incommensurable worldviews compels us to imagine two distinct worldviews that are radically incongruent. By doing this, the relativist argument forces us to assume the vantage point of an omniscient narrator that the argument itself instructs us to deny. Reliance on these features implies a bird's-eye view of un-interpreted world, a world that is experienceable and observable in basically the same way by people who are separated by space and time and merely name, analyse and describe in diverging ways an otherwise shared factual reality. Language philosopher Donald Davidson convincingly unmasked assumptions of this nature as an illogical construct belonging to the so-called 'Third Dogma of Empiricism. ${ }^{22}$ The idea of radical incommensurability or radical incomparability that critics of the factual approach in comparative law appear to support, is, therefore, unattainable. ${ }^{23}$

The better view is that there is nothing beyond the world-as-we-know-it. The 'foreign', the 'different' or the 'other' are already within the world in which we find ourselves. We may find certain expressions of language or the legal formants of foreign law incomprehensible, but that assessment would be measured by the benchmarks of everything we know and apprehend. We understand these expressions and legal formants as part of an 'outside' because they are part of the intelligible 'within'. If we understand something as something, we can no longer say it originates or resides beyond the world as we experience and observe it. There would not be a beginning of understanding anything as anything without

21 The following summary critique of cultural and linguistic relativism is based on the critical analysis put forward in C.J.W. Baaij, 'Confronting the Conjecture of Cultural Incommensurability in Comparative Law' (2014) 25(2) King’s Law Journal 287, 294-300, and the more elaborate philosophical argument developed in C.J.W. Baaij, Legal Integration and Language Diversity (Oxford: Oxford University Press, 2018) 189-200. The thrust of the argument takes inspiration from language philosopher Donald Davidson's rejection of the idea of 'conceptual schemes' proposal of a 'principle of charity' in D. Davidson, 'Belief and the Basis of Meaning' (1974) 27(3/4) Synthese 309 and D. Davidson, 'On the Very Idea of a Conceptual Scheme' (1974) 47 Proceedings and Address of the American Philosophical Association 5.

22 The idea of the separateness of reality and our experience of it, was dubbed by language philosopher Donald Davidson as the 'Third Dogma of Empiricism'; see D. Davidson, 'On the Very Idea of a Conceptual Scheme' (1974) 47 Proceedings and Address of the American Philosophical Association 5, 11.

23 Here, incommensurability and incomparability are listed as the same or similar aspects of a comparative legal analysis. A more nuanced breakdown, however, shows that the two concepts are distinct, albeit closely related; see C.J.W. Baaij, 'Confronting the Conjecture of Cultural Incommensurability in Comparative Law' (2014) 25(2) King's Law Journal 287, 291-294, and C.J.W. Baaij, Legal Integration and Language Diversity (Oxford: Oxford University Press, 2018) $180-183$ 
already having understood it to be something, even if it is something of which we cannot make any sense. ${ }^{24}$

Hence, the relativist case against projects like the Common Core is weak at best. Any comparative legal project will necessarily be built on an elementary foundation of sameness. If we reject the relativist critique for the reasons stated above, nothing precludes the comparatist from assuming a bedrock of shared reality across cultures and languages. The foundation of sameness underlying the comparative analysis, however, involves a rudimentary commensurability of cultures, languages and anything within them, including the law. It does not excuse the legal translator or legal comparatist from disregarding or concealing any differences and presuming or presenting the distinct jurisdiction as similar or the same. The foundation of sameness is a basic prerequisite for intelligibility, not a restriction to, or call for, identity. It allows for the comparatist to find anything from exceptionally similar to extremely different.

\section{THE TRANSLATION METHOD FOR LEGAL CONCEPTS AND INSTITUTIONS}

To aid the editor-comparatist in expressing contrast and distinction between the compared jurisdictions, ${ }^{25}$ reporter-translators reported solely on their legal system and minimised the comparisons with other legal systems. When it comes to national reports containing explicit comparisons, we asked reporters to refrain from including comparisons with other national legal systems or European or international instruments such as the UN Convention on Contracts for the International Sale of Goods (CISG). ${ }^{26}$ Among all participants of a study, national reporters are the best experts on the national system they are reporting on. Any report that contains a comparison with another legal system implies claims about a legal system beyond the one reported on, one that the reporter is not an expert in and about which a different national expert might already be reporting. Moreover, the method expressly or implicitly used by that national reporter might diverge from the method used by the editors. Hence, national

24 This follows Donald Davidson's 'Principle of Charity' ('Belief and the Basis of Meaning' (1974) 27(3/4) Synthese 309, 321; 'On the Very Idea of a Conceptual Scheme' (1974) 47 Proceedings and Address of the American Philosophical Association 5, 19), but also Hans-Georg Gadamer's 'Fusion of Horizons' (Truth and Method, trans. J. Weinsheimer and D.G. Marshall (3rd edn, London: Continuum, 1975/ 2004) 304, 336, 361-362, 366).

25 Bussani and Mattei confirm that the Common Core Project is not partial to finding similarities over differences: see M. Bussani and U. Mattei, 'The Common Core Approach to European Private Law' (1997) 12 Columbia Journal of European Law 344, 340-341.

26 United Nations Convention on Contracts for the International Sale of Goods, S. Treaty Doc. 98-99 (1983). 
reports containing comparative analyses disturb or compromise the eventual comparison of the national reports. Hence, any elements that they find to be characteristic of their legal system should be explained without reference to foreign law. If the reporter thought particular comparative legal findings were relevant to the project, they were asked to share these insights with the editors in a separate communication.

Likewise, the translations the reporters offered contained as little comparative analysis as possible. While comparative legal analysis is impossible without translation if the jurisdictions involved use different language, legal translation can in fact take place without comparative legal analysis even if imperfectly. When a comparative study includes jurisdictions using different languages, there is no comparing legal texts whatsoever without translation. Imagine a comparatist who cannot read the language of the foreign legal system. She or he might on its face recognise the text as text, that is to say, a document with words and syntax having meaning and conveying a message rather than a piece of paper with randomly dispersed ink. Yet, beyond this, the comparatist would not be able to have any idea of what the document conveys about the foreign legal system - or whether it narrates anything related to law altogether.

Conversely, for the national reporters to translate the information about their legal systems into English, strictly speaking, no comparative analysis is needed. An individual may carry out a legal translation without having any comparative legal knowledge. The eventual translation might turn out to be seriously deficient, missing specific legal context and overlooking the many subtle legal niceties. Yet a genuinely flawed legal translation is still a legal translation. Hence, while comparative legal analysis cannot even get off the ground without an antecedent translation, legal translation does not necessitate a precedent comparative legal analysis, even if resulting in a poor translation.

The translations offered by the national reporters are essential for the editor's comparative analyses. Given the division of labour between reporter-translators and editor-comparatists, it was vital, therefore, that all national reports stayed as close to the language and expression of the language of their legal system while maintaining intelligibility in English, the language of the comparative project. The reporter-translator is therefore advised to follow the following four steps in conveying the meaning of legal concepts and institutions.

\subsection{STEP 1: USING INVERTED COMMAS}

The first step is to signpost to the reader that a particular word is a legal term or legal phrase referring to a domestic legal concept or institution. The word is best placed within single inverted commas. This applies to all national reports, regardless of whether the language of the reporter's legal system is English or not. 


\subsection{STEP 2: USING ORIGINAL LANGUAGE FOR DOMESTIC LEGAL CONCEPTS}

The second step is to list the legal terms in the original language of the legal system in question. Hence, if the language of a reporter's legal system is not English, the legal term or word naming a domestic legal concept or legal institution should be in the language of the reporter's legal system. Even if the editor-comparatist and the eventual reader cannot understand the term, it will be apparent to all that the term is foreign to the English language or legal system. In a Dutch report, this method might result in a sentence like this:

Courts tend to solve this problem by appealing to the concept of 'aanvullende werking van de redelijkheid en billijkheid?

The reporter might be tempted to use the English legal term 'good faith' to refer to this domestic legal concept. This should be avoided, however, because the report risks slipping into a covert comparative analysis suggesting that 'de aanvullende werking van de redelijkheid en billijkheid' is the same or similar to the English concept of good faith, and thus tainting the editor's comparative analysis. The reporter might indeed believe these concepts are the same or at least similar enough to be translated as such. The editor might come to this conclusion as well. Nevertheless, the editor's conclusion should follow from a comparative analysis of 'clean' data provided in the national reports. To this end, the national report should use language that is as free as possible from hidden, antecedent comparisons.

\subsection{STEP 3: ADDING A (LITERAL) ENGLISH TRANSLATION}

The third step is for the national reporter to add an English translation directly following the domestic legal term, placed in square brackets. This step helps to inform the editor-comparatist and the eventual readership of the semantic meaning of that domestic legal concept in the English language. After all, using a domestic legal term in the original language may convey the concept's foreignness, but it might also prevent the reader from understanding its conceptual meaning or role as a legal formant, and thus prohibits a meaningful comparison.

By adding an English translation, the sentence in the Dutch language version in our example would be expanded as follows:

Courts tend to solve this problem by appealing to the concept of 'aanvullende werking van de redelijkheid en billijkheid' [the complementary effect of reasonableness and fairness]. 
To avoid slipping into a covert comparison after all, the English translation should be as literal as possible. ${ }^{27}$ In fact, the reporter should not shun odd or absurd results. Here, it is better to convey the foreignness of the domestic legal concept within the English language than to use familiar language and inadvertently suggest that the domestic concept is similar to or the same as the English legal concept. Again, the national reporter might deem the concepts alike, but here she or he is acting as a national reporter, not as comparatist.

\subsection{STEP 4: ADDING AN EXPLANATION OR DESCRIPTION}

The fourth step entails the reporter adding an explanation or description of the domestic concept in the English language. This should follow the English translation directly, hence it also features in the body of the text. This step is geared toward clarifying the possibly odd-looking English translation. Again, for the reasons stated above, the subsequent explanation should under all circumstances avoid referencing English or other foreign legal concepts or institutions that the reporter may consider to be equivalent or near-equivalent terms. Instead, the explanation should be in layman's terms, that is, without further domestic legal terminology. Eventually, the Dutch rendition of a domestic legal term in the English language in our example would look like this:

Courts tend to solve this problem by appealing to the concept of 'aanvullende werking van de redelijkheid en billijkheid' [the complementary effect of reasonableness and fairness]. This concept entails that ... (and so on).

Naturally, while a literal translation between square brackets will not be required if the language of the national legal system is English, further description or explanation should still be provided in the text directly after the use of the term. This would read, for example:

Reference is often made to the 'four-corner rule.' This rule entails that ... (and so on).

27 See for a more elaborate defence of literal legal translation for the purpose of comparative legal research, C.J.W. Baaij, 'Legal Translation and the "Contamination" of Comparative Legal Research' in S. Glanert (ed.), Comparative Law: Engaging Translation (New York: Routledge, 2014) 112-118). In legal scholarship, literal legal translation does not find broad support. The last notable defenders of literal translation in legal scholarship were Boyd White (Justice as Translation (Chicago: University of Chicago Press, 1990) 200, 252-253). Today, Lawrence Venuti is the most vocal proponent of literal over freer methods of translation in general and literary translation studies, see e.g. L. Venuti, The Translator's Invisibility: A History of Translation (2nd edn, London: Routledge, 1995/2008). 
Furthermore, the method for introducing legal terms in the English language by national reporters from non-English-speaking jurisdictions applies also to citations from, for example, court opinions, authoritative texts and textbooks. The quotation in the body of the text should use the original language of one's jurisdiction, and subsequently add a translation of the quote in the footnote when the original language is not English. Here, too, the translation should be as literal as possible, without using any legal terms that the reporter deems the legal equivalent in the English language. As with using domestic legal terms, the reporter best explains the significance of the quote in the body of the text. Again, the explanation should occur in layman's terms and avoid further domestic legal terminology as much as possible.

\section{CONCLUDING REMARKS}

The methodology that the editors have chosen to manage the challenges intrinsic to comparative analyses, translation and language in general is not a guarantee of perfect cross-legal and cross-lingual communication. The reason is not because this method falls short of achieving full precision and flawlessness. Rather, it is because there is no such thing as 'perfection' in communication. Assuming that there is implies a bird's-eye view of an 'un-interpreted world' that Donald Davidson has shown to be an inconsistent construct. That is to say, there is no extra-lingual standard by which anyone would be capable of claiming a point of unobstructed communication. Hence, those engaged in cross-lingual comparative legal analysis should not aim to achieve purity of content. Consequently, the methodology chosen in this book is geared toward minimising the risk of implicit inferences in one person's observations 'contaminating' the observations of others. The editors seek to increase the reliability of the findings of the book procedurally by advancing a division of labour between reporters and comparatists. 